\title{
ENCARCERAMENTO E EXTERMÍNIO DE PARTE DA JUVENTUDE BRASILEIRA COMO POLÍTICA DE CONTROLE DA CRIMINALIDADE E DO MEDO
}

\author{
Laís Gorski ${ }^{1}$ \\ Jair Silveira Cordeiroº
}

\section{RESUMO}

O artigo problematiza os sujeitos sociais considerados inimigos ou descartáveis. Objetivase compreender como a sociedade e o Estado criam mecanismos para estabelecer que os adolescentes e jovens, pobres, negros de 14 a 29 anos de idade, moradores das periferias das cidades brasileiras são a categoria social considerada inimiga, descartável. Para tanto, com base na revisão bibliográfica e em fontes primárias busca-se demonstrar que o crescente aumento no encarceramento e o extermínio físico destes adolescentes representa que a sociedade e o Estado brasileiro elegeram este grupo social como os responsável pela crise da criminalidade e pela cultura do medo no Brasil.

Palavras chaves: sociedade, medo, adolescente infrator, inimigo, cultura do medo.

\section{JUSTICE AND EXTERMINATION OF BRAZILIAN YOUTH AS A CONTROL POLICY FOR CRIMINALITY AND FEAR}

\begin{abstract}
The article deals with social subjects that are considered enemies or disposable. It seeks understanding of how society and Brazilian State create mechanisms to establish that a large part of the population of young people, between 14 and 29 years old, male, black, residents of the surroundings areas are a social category considered enemy, disposable and inconvenient. Through bibliographic review and research in primary sources, it's possible to perceive the increasing of incarceration of adolescents and physical extermination of the young people that society and the Brazilian State elected as responsible for the crisis of urban violence in Brazil.
\end{abstract}

Key words: society, fear, adolescent offender, enemy, culture of fear.

\section{INTRODUÇÃO}

As últimas quatro décadas foram marcadas por profundas transformações nas formas de vida dos sujeitos em diversas partes do planeta. A consolidação do processo de globalização econômica, política, social e cultural vem promovendo mudanças que têm

\footnotetext{
${ }^{1}$ Graduada em Direito pelo Centro Universitário Ritter dos Reis. Especialista em Direito Penal e Políticas Criminais pela Universidade Federal do Rio Grande do Sul. Mestranda em Direito e Sociedade pela Universidade La Salle, bolsista CNPQ/CAPES.

${ }^{2}$ Mestre e Doutor em Ciências Sociais pela Pontifícia Universidade Católica do Rio Grande do Sul. Mestrando em Direito e Sociedade pela Universidade La Salle.
} 
afetado as interações entre os sujeitos sociais, o que gera novos tipos criminais e novas formas de manifestações da violência, colocando em cheque as tradicionais formas de resolução de conflitos nas sociedades ocidentais. Tais transformações acarretaram surgimento de novos atores na cena criminal brasileira, como os adolescentes autores de atos infracionais e os novos grupos sociais, ambos grupos tidos como inaptos a viver de acordo com os novos padrões de desenvolvimento econômico e social da nova ordem globalizada. Em outras palavras, os jovens de 14 a 29 anos, pobres, negros e moradores das periferias das grandes e médias cidades brasileiras.

Assim, este estudo busca demonstrar, por meio de dados, que a sociedade e o Estado brasileiro consideram um determinado grupo social como inimigo ou descartável, além de compreender quais os mecanismos acionados para determinação desta parcela da população. Para tanto, norteia-se a pesquisa com a questão de como o medo e as percepções de senso comum são capazes de contribuir para o crescente aumento do encarceramento dos adolescentes e para o extermínio de parcela de jovens no Brasil.

Buscando não esgotar o tema ou encontrar todas as respostas para estas questões que Bauman (1998) denomina de "o mal estar da pós-modernidade", o trabalho aqui introduzido intenta, através de pesquisa em fontes primárias e de revisão bibliográfica pertinente ao tema uma reflexão crítica acerca da marginalização de parcela da juventude brasileira, tornando-os atores da cena criminal brasileira tanto como algozes, quanto como vítimas. Esta situação fez com que setores da mídia e da sociedade brasileira, através de noções de senso comum, vinculassem tal grupo social como os principais responsáveis pelo crime e pelo medo urbano. E, diante desta "pseudo" constatação, parcela dos setores formadores de opinião intentam introjetar na sociedade brasileira que os grupos sociais tidos como inimigos merecem ser excluídos do meio social, seja pelo encarceramento, ou pelo extermínio físico.

Ainda, justifica-se o estudo pela necessária reflexão acerca da opção tanto da sociedade, quanto do Estado brasileiro por este caminho frente a parcela da juventude, a fim de demonstrar o equívoco na escolha das políticas de combate à criminalidade e a falta de disposição em garantir direitos fundamentais a uma camada populacional que sofre cotidianamente a falta de acesso a saúde, a segurança, a educação, ao trabalho digno, entre outros. Isto porque, ao contrário do que pensa a sociedade mais ampla, conforme os dados que esta pesquisa visa demonstrar, não são os adolescentes infratores os principais 
causadores da criminalidade violenta no país, bem como não é a parcela estigmatizada da juventude causadora dos problemas sociais, mas sim, é vítima de extermínio causados pela falta de segurança e falha das demais políticas públicas garantidoras de direitos.

Preliminarmente, serão trazidas as importantes modificações sofridas no cenário nacional e mundial pelos efeitos da globalização, pois elas levam ao entendimento das noções modernas de risco, perigo e medo experimentadas pela sociedade. A partir disto, quer-se compreender como este medo importa na vida das pessoas e influi nas relações estabelecidas entre os diferentes grupos sociais e as instituições.

Em seguida, adentrar-se-á ao medo na sua forma personificada, ou seja, será discutido a quem se atribui o vício de inimigos da sociedade. Para então realizar análise de dados publicados por diversos estudos e relatórios nacionais, a fim de compreender se o estigma introjetado pela sociedade brasileira condiz com a veracidade real dos fatos. Isto é, através do estudo e comparação das estatísticas realizadas ao longo dos anos, intui-se demonstrar se os adolescentes e jovens, negros, pobres e moradores dos núcleos periféricos dos grandes e médios centros urbanos nacionais são os maiores causadores da criminalidade no Brasil e que não faz sentido o estado e a sociedade brasileira buscar exterminá-lo.

\section{O IMPACTO DAS TRANSFORMAÇÕES GLOBAIS NA VIOLÊNCIA, NA CRIMINALIDADE E NO MEDO DOS CIDADÃOS}

De acordo com Santos (2000) e Bauman (1998), o final do século XX caracteriza-se como um período histórico de profundas transformações econômicas, políticas, sociais e culturais em todas as sociedade do planeta. $\mathrm{O}$ avanço e a consolidação do processo de globalização econômica, financeira, tecnológica, política e cultural afeta todas as dimensões da vida social e subjetiva dos sujeitos neste contexto histórico.

O impacto da tecnologia informacional no paradigma econômico faz com que a economia deixe de ser centrada na produção e passe a ser baseada essencialmente no consumo. Segundo Beck (1997), a sociedade que emerge deste processo é uma sociedade de consumo e pós-industrial, marcada por uma economia de serviços virtual e informacional, e uma sociedade de risco caracterizada pela incapacidade das instituições tradicionais da sociedade industrial de responderem satisfatoriamente as demandas dos indivíduos. 
A consolidação do processo de globalização nas diferentes esferas da vida e do sistema mundial não significa uma extinção dos modos de vidas locais e nacionais, pelo contrário, ela faz a conexão de ambas as dimensões, elevando os graus de risco nas mais distintas relações sociais. Para Giddens (1997), a sociedade de consumo globalizada conecta as "grandes" questões sociais às "pequenas" questões da vida cotidiana das pessoas. Prova disso é que o ato individual de uma pessoa em comprar uma determinada peça de roupa ou algum tipo específico de alimento pode refletir em questões globais como, por exemplo, a sobrevivência de alguém que vive do outro lado do mundo, por tal fato representar uma contribuição na deterioração ecológica do planeta, prejudicando não só aquela região, mas toda a humanidade.

As transformações tecnológicas, econômicas e sociais das últimas décadas dão um dinamismo acelerado nas relações sociais e decorrem da possibilidade de separação do tempo e do espaço em que as interações se estabelecem. Conforme Mendes, Reis e Simioni (2014), a noção de desencaixe trazida por Giddens, é fundamental para o entendimento das interações na contemporaneidade, pois o que acontece neste momento histórico é um deslocamento das relações sociais de contextos específicos para uma reestruturação por meio de extensões indefinidas de tempo-espaço. Os Autores salientam, ainda que, para Giddens a confiança é um elemento central para compreensão do mundo moderno, visto que, ela pressupõe conhecimento e, assim, as consequências das ações em que um resultado pode ser conhecido, logo, devendo ser entendido como um risco.

Nesta perspectiva moderna, o conhecimento dos resultados das ações se dá através dos "sistemas peritos", que são capazes de produzir o desencaixe das relações sociais por meio da geração de expectativas para além do persente. Estes sistemas peritos seriam sistemas de excelência técnica ou de competência profissional capazes de organizar grandes áreas dos ambientes material e social em que se vive. (GIDDENS, 1997). Constata-se, então, que a confiança pressupõe o conhecimento das circunstâncias de risco. (MENDES, REIS e SIMIONI, 2014). Isto é, um indivíduo que em suas ações não considera as alternativas está numa situação de crença, enquanto que aquele que considera as alternativas baseado em conhecimento e tenta calcular os riscos age com confiança e mínima previsibilidade.

A partir disto, os autores concluem sobre os ensinamentos de Giddens que a confiança, os sistemas peritos, o risco e o perigo estão intimamente ligados, quer dizer, as 
ações dos sujeitos baseadas no risco pressupõe que o conhecimento/sistema perito seja utilizado como forma de referenciar a melhor ação a seguir. Já, por outro lado, as ações baseadas no perigo decorrem da crença dos sujeitos que algo dará certo, mas sem base no conhecimento. Neste cenário, o direito enquanto sistema perito é um importante instrumento de segurança, na medida em que estabiliza os conflitos sociais e garante a continuidade das interações.

Por outro lado, a complexidade das transformações em curso no fim do século XX também afeta a capacidade das sociedades em mediar os conflitos eficazmente, o que resulta na expansão e na complexificação das práticas sociais violentas associados aos atos criminosos. A violência torna-se um fenômeno social que permeia as diferentes relações sociais e, segundo Porto (2010), ela, em um contexto contemporâneo ocidental, tem origem neste complexo cenário social marcado pela necessidade de adaptação das condutas e dos valores, fazendo surgir os estranhamentos, as contradições e os conflitos entre os diversos atores sociais. Isto transforma a violência para muitos grupos sociais, em diferentes territórios, no principal instrumento social capaz de ser acionado como forma de resolução de conflito e como forma de organização das relações sociais, tanto no âmbito institucional, quanto no âmbito das relações interpessoais.

$\mathrm{Na}$ contemporaneidade a violência torna-se um fator causador de práticas criminosas e ocorre de forma sistêmica e "organizada", envolvendo atores de diferentes extratos sociais e de diferentes instituições públicas ou privadas. A configuração das práticas criminosas passa a se dar pela multiplicidade complexa dos ilimitados e variados comportamentos que a sociedade contemporânea produz. Ao mesmo tempo em que ocorre o aumento de práticas criminosas tradicionais como roubo e o furto, também há a incorporação no cenário criminal, não somente nos países do Ocidente, mas em âmbito global, de novos crimes como: a falsificação de cartões de crédito, a pirataria nos sistemas de informática com vistas a sabotagem dos sistemas de comunicação eletrônica, a manipulação do sistema financeiro, a falsificação de produtos, o tráfico de seres humanos e de drogas ilícitas, as fraudes contra o patrimônio público e a corrupção, além dos atos terroristas em diversos continentes do planeta. (MAILARD, 1994).

Diante deste cenário, o medo é outro elemento que passa a ter importância fundamental no cotidiano dos sujeitos, influindo diretamente nos tipos de interações que estes estabelecem entre si, entre os diferentes grupos sociais com os quais interagem e com 
as instituições que medeiam suas relações sociais nos territórios e cidades em que estão situados. Para Bauman (2009), o medo é um sentimento que toda criatura viva conhece, logo, os seres humanos ao enfrentarem uma ameaça reagem com a fuga da situação ou agressão ao fator causador de tal sentimento.

Nesta mesma linha, o sociólogo acrescenta que os humanos conhecem uma espécie de medo "de segundo grau ou derivado", o qual orienta seus comportamentos existindo ou não a situação de ameaça imediata e presente. $\mathrm{O}$ "medo derivado" caracteriza-se como o sentimento de ser suscetível ao perigo e uma sensação de insegurança e vulnerabilidade diante de uma ameaça impossível de se escapar.

O medo relacionado à insegurança na contemporaneidade vincula-se diretamente ao medo do crime e dos criminosos, que passam a atuar de forma organizada e hierárquica, influenciando as ações dos agentes de Estado (políticos/forças de segurança) e controlando as populações que vivem em vastos territórios nas grandes e médias cidades do mundo. $\mathrm{O}$ desmantelamento do Estado providência na Europa, bem como o esvaziamento das políticas públicas em outros países, como o Brasil, e o abandono dos sujeitos ao individualismo neoliberal foram os elementos potencializadores do crescimento do medo nas sociedades contemporâneas. (BAUMAN, 2009)

Com a modernidade globalizada, aprofundam-se os processos de exclusão de diversos grupos sociais que são descartados do processo produtivo e considerados inúteis e inábeis, assemelhando-se aos tidos como criminosos. Por conseguinte, tais grupos sociais passam a ser vistos como sujeitos a serem impedidos de criar problemas e mantidos a distância da comunidade que respeita as leis. Bauman (2010) afirma que "não há dúvidas que os tempos modernos produziram realizações espetaculares. O problema é que agora estamos diante não apenas dos benefícios, mas também dos custos do progresso tecnológico."

Nos dizeres de Fernandes (2009), a segregação social leva à segregação espacial. As cidades acabam por sofrer o impacto deste processo e passam a ter duas dimensões: uma que se relaciona através da tecnologia com outras cidades nacionais, internacionais e globais e outra de caráter local que vive preocupada com as necessidades e dilemas do diaa-dia.

Para Bauman (2009), tal cenário evidencia dois modos de vida separados, segregados. Os que se relacionam com a tecnologia e com o acesso aos melhores bens de 
consumo são cidadãos globais; os outros cidadãos que forjam sua existência nos elementos identitários étnicos e nas demandas da sua comunidade. As pessoas de "primeira fila" não se identificam com o lugar onde moram, já as pessoas da "última fila" estão condenados a permanecer no lugar e buscar a sobrevivência diária.

Desse modo, é nas cidades que as interações das demandas globais e os anseios locais se realizam. São nestes espaços urbanos que as identidades locais são negociadas, modeladas e remodeladas. Contudo, Bauman (2009) considera que a política como instrumento adequado destas negociações ainda são locais e as questões globais só entram no âmbito das questões políticas quando repercutem em questões locais, o que transforma a cidade em um depósito de problema causado pela globalização em que os cidadãos devem encontram as soluções locais para os problemas que são globais.

No âmbito brasileiro, o medo é associado a criminalidade e assume características específicas, afetando a vida e as formas de interações dos sujeitos nos contextos urbanos marcados pela degradação da sociabilidade e pelo enfraquecimento da cidadania. Eis alguns dos grandes dilemas da sociedade contemporânea: sociedade de risco, transformações da criminalidade violenta, aumento do medo no cotidiano dos cidadãos, implementando uma cultura do medo em esfera local e global.

Caldeira (2000) afirma que o sentimento de medo da sociedade não está relacionando com o grau de criminalidade de dada região, quer dizer que a sensação de segurança dos indivíduos não está diretamente ligada à ausência do crime, mas sim do distância social. $\mathrm{O}$ sentimento de temor é alçado a um nível cultural, isto é, uma cultura do medo que está presente nas grandes cidades brasileiras, representando o somatório dos valores, dos comportamentos e do senso comum que, vinculado com a questão da criminalidade, reproduz a ideia de insegurança e perpetua uma forma de dominação pelo autoritarismo. (PASTANA, 2005)

Uma das consequências deste fenômeno são modificações nas cidades, que passam a expressar a "arquitetura do medo". As casas são cercadas por muros mais altos e por complexos sistemas de segurança eletrônicos. Pastana (2005) exemplifica isto pela construção de enclaves fortificados tanto para os condomínios residenciais, quanto para as áreas comerciais como os shoppings centers.

Além disso, a cultura do medo também gera discriminações, seja devido a algum estereótipo social que está vinculado a algum tipo de delito específico ou pela simples 
associação de certos crimes a determinada categoria social. Comumente, a sociedade brasileira atribui o crime de tráfico de drogas a adolescentes ou jovens, pobres, negros e moradores das periferias dos grandes centros urbanos. Anthony Giddens (2000) definiu isto como um processo de reversão, atribuindo o conceito de "dialética do controle", que reverte a cultura da humilhação em cultura do medo.

Importa trazer à reflexão o papel da imprensa e das autoridades - as políticas como as policiais - que contribuem de forma significativa para a existência da cultura do medo. Se de um lado, a imprensa não reflete a realidade e a intensidade dos eventos quando deixa de notificar os pequenos furtos e agressões, que são os delitos mais frequentes, de outro, os estupros, sequestros e tráfico de drogas são noticiados com maior intensidade, mesmo sendo praticados em menor quantidade. Pastana (2005) compartilhando desta visão, expressa que pelos meios de comunicação, os políticos e as autoridades policiais propõem medidas populistas, como maior encarceramento e uso de força bruta contra os ditos vitimizadores, como uma forma de solução dos problemas relacionados à violência.

Ao contrário do que se possa imaginar, a cultura do medo não é algo que surja naturalmente e sem nenhum interesse por trás, mas ela atua como um instrumento de dominação dos grupos hegemônicos da sociedade brasileira sobre as camadas sociais dominados e oprimidos. Em uma sociedade classista e desigual como a brasileira a dominação não se dá somente pela coerção, mas também pela difusão de uma visão de mundo que quer fazer crer ao oprimido que o autoritarismo e arbítrio são mecanismos necessários e circunstanciais para reverter a sensação de insegurança e medo em que vivem e, por isso, a violência precisa ser controlada a qualquer preço, seja com mais punição, encarceramento ou até mesmo com a pena de morte. (PASTANA, 2005)

Por sua vez, a cultura do medo tem como pilar de sustentação a transmutação das formas de práticas criminosas na contemporaneidade. Se até a década de 1960 os crimes mais cometidos estavam associadas aos crimes passionais, a disputas entre vizinhos e brigas de bar, a partir de 1970, com a consolidação da industrialização do país e a migração da população rural para os grandes centros urbanos, a criminalidade passou a estar associada ao "crime organizado", quer dizer, as atividades do jogo do bicho, do tráfico de drogas ilícitas e das "milícias policiais". Tal mudança proporciona a inserção de novos atores sociais nas práticas delituosas e uma nova configuração criminal. 
Segundo Adorno (1998) e Feltran (2010), a criminalidade violenta urbana no Brasil caracteriza-se por ser praticada por sujeitos vinculados as organizações criminosas que exploram o tráfico de drogas ilícitas e que efetuam os crimes de homicídio, latrocínio e roubos por relações conexas ao tráfico de drogas envolvendo a venda, a gestão, o controle e a segurança deste negócio. Na mesma linha Santos (2000) e Zaluar (2004, 1997) consideram que a criminalidade violenta geradora de medo na sociedade brasileira configurou-se nas últimas décadas como urbana, associada ao crime de tráfico de drogas ilícitas cujos protagonistas, sejam como vítimas ou agressores, são sujeitos jovens, entre 14 e 24 anos, pobres e negros moradores nas grandes e médias cidades e regiões metropolitanas do país.

O envolvimento de parte dos adolescentes e dos jovens brasileiros com o crime organizado não possui uma causa única. Além das precariedades impostas pela pobreza e pela falta de políticas públicas, certamente, as redes de sociabilidade acessadas pelos jovens, a invisibilidade social destes e a valorização da cultura do dinheiro, do poder, da violência e do consumo vinculados ao tráfico de drogas ilícitas influenciam na adesão dos jovens nas práticas criminosas. Soares, Bill e Athayde (2005), bem como Carmo (2000) e também Fonseca (2004), retratam tal realidade e demonstram que a adesão dos adolescentes e jovens ao mundo do crime é um fato social complexo e que a reversão deste quadro exige ações eficazes por parte do Estado e da sociedade.

Tal cenário nacional enquadra e estigmatiza uma parcela da população jovem do Brasil - e, quem diz estigma, diz pobre, negro e residente das periferias nacionais -, como um dos agentes causadores do medo social vivido pelos brasileiros. Sincronicamente, a pressão de alguns setores sociais e a difusão midiática que propagam a ideia de que há um crescimento no número de crimes violentos praticados por tal população terminam por colaborar para que a percepção social da violência juvenil seja alargada.

Na percepção de Volpi (2001) existem três mitos relativos a delinquência juvenil que resultam ser a principal causa dos problemas de segurança pública no Brasil, são estes: o hiperdimensionamento do problema, a alta periculosidade do adolescente e a impunidade que os afeta. Para o autor, o problema é um falso problema, pois, segundo dados do Censo Penitenciário Brasileiro, do ano de 2000, constatou-se que, em 1994, havia no Brasil oitenta e oito presos adultos para cada cem mil habitantes, enquanto que havia, no mesmo período, três adolescentes privados de liberdade, por cumprimento de medida 
socioeducativa, para cada cem mil habitantes. Tal proporção manteve-se nos três anos seguintes, mesmo com aumento da população carcerária brasileira, o que possibilita afirmar que a propagação do pânico sobre a violência juvenil não encontra respaldo nos dados oficiais.

No que tange o mito referente à periculosidade juvenil, constata-se que a percepção de que os adolescentes cada vez mais cometem crimes violentos é equivocada. Ainda, os percentuais dos atos infracionais praticados por adolescentes correspondem a menos de dez por cento dos crimes praticados por adultos e que, dos delitos praticados somente dezenove por cento são considerados graves: homicídio, latrocínio ou estupro. Infere-se, portanto que, os crimes praticados pelos adolescentes correspondem a menos de dois por cento do total de delitos cometidos no período da pesquisa da Volpi (2001).

No que se refere a noção de impunidade juvenil, Volpi (2001) revela que ela tem origem na noção de senso comum de que o Estatuto da Criança e do Adolescente não satisfaz a função punitiva aos adolescentes que cometem atos infracionais. Para o autor, tal percepção é equivocada, pois, as medidas socioeducativas são compostas de uma série de medidas punitivas, inclusive a privação de liberdade por até três anos, conforme a gravidade do ato infracional, o que em alguns casos representa medidas mais severas as penas atribuídas aos adultos para o mesmo tipo de delito.

Atualmente, existem alguns Projetos de Leis no Congresso Nacional ${ }^{3}$ brasileiro tratando da redução da maioridade penal ou do aumento do tempo de internação aos adolescentes que cometem determinados atos infracionais. O cenário acima exposto explica tal fato e também revela que o adolescente autor de ato infracional, bem como os demais estigmatizados representam o "inimigo" que a sociedade brasileira quer e precisa vencer, fazendo desaparecer do seu convívio social, seja pelo encarceramento, seja pela via do extermínio físico.

\section{O INIMIGO E O EXTERMINÁVEL NA SOCIEDADE BRASILEIRA CONTEMPORÂNEA}

\footnotetext{
${ }^{3}$ Para citar alguns, tramitam no Senado Federal as PECs de números 33/2012, 74/2011, 21/2013, 115/2015. 
Em perspectiva histórica, o mundo ocidental sempre atribuiu a determinadas categorias sociais ou indivíduos a pecha de inimigos da sociedade. Se na Idade Média a mulher/bruxa e os feiticeiros/não cristãos eram considerados os inimigos, no limiar do período medieval para a modernidade os sujeitos que violavam o contrato social dos cidadãos na busca por uma sociedade civilizada eram considerados bárbaros inimigos a serem combatidos. O rompimento das estruturas medievais tornou o Estado o ente responsável pela mediação dos conflitos sociais e pela punição aos sujeitos violadores das normas assumidas no contrato social. As sociedade modernas constituíram um amplo leque de instituições formais e não formais com o intuito de realizar e manter o controle social sobre os sujeitos que não se adaptavam as formas de convívio e de produção da sociedade capitalista que emerge no mundo ocidental. O sistema político hegemônico estabeleceu então estruturas jurídicas penais para exercer o controle sob os cidadãos, assim como estruturas não jurídicas capazes de exercer o controle dos sujeitos inimigos deste sistema social.

De acordo com França (2012), a história ocidental registrou diversos grupos como “inimigos”. $\mathrm{Na}$ Idade Média a peste negra que devastou milhares de pessoas, devido ao desconhecimento de suas causas, fez com que a sociedade projetasse nos estrangeiros, nos viajantes e nos marginais os causadores do mal. Além deles, os judeus, os leprosos eram considerados os inimigos da população por trazerem o mal aos demais. Ainda segundo o autor, o século XX foi também próspero em criar grupos sociais inimigos da sociedade e do Estado soberano. O anti-semitismo tornou-se um dos alicerces dos governos fascistas na Europa; a criação do Estado de Israel na região da Palestina fez ressurgir a inimizade entre dois povos e mais tarde o planeta se divide em dois blocos: capitalistas e comunistas. $\mathrm{O}$ aumento dos atos terroristas e a sua criminalização pelos países do ocidente manteve a divisão do mundo em dois blocos, agora: ocidente versus oriente, o que resultou no surgimento de novos inimigos como Saddam Hussein e Osama Bin Laden.

A compreensão de que cada época histórica cria em seus núcleos de convivências, grupos ou indivíduos que se caracterizam como inimigos da sociedade e do Estado não esgota a questão, pois, uma compreensão mais abrangente do fenômeno político-social está atrelada a como estes inimigos surgem dentro do contexto social. Assim, na esteira de França (2012), este fenômeno decorre de uma construção estrutural do discurso do poder político-punitivo que cada época histórica produz. Ou seja, a inconveniência do existir 
revela-se, a partir, de uma distinção política (amigo e inimigo) e alcança a concretização plena na figura do criminoso moderno, forjado do contrato social que se tornou objeto do poder-saber penal.

A partir do final século XVII houve uma transmutação nos tipos de crimes no mundo ocidental. Ocorre a diminuição dos crimes sangrentos e o aumento dos crimes patrimoniais. Ao mesmo tempo, com inspiração dos filósofos iluministas, ocorre a mudança do sistema punitivo, o suplício público sobre o corpo do acusado dá lugar ao controle da alma do acusado através da domesticação dos corpos.

O projeto moderno do sistema jurídico penal caracteriza-se pelo controle prévio da conduta penal proveniente do contrato social, livre e conscientemente aderido pelas pessoas que se submetem as penalidades em decorrência de um deslize ocasional na conduta esperada. Consequentemente, o processo penal assume o procedimento contraditório e público, orientado pelas limitações do poder punitivo do Estado e defesa do polo débil da relação processual e uma vez constatada a culpabilidade aplica-se a punição: a prisão. (FRANÇA, 2012)

Seguindo as concepções foucaultianas, França (2012) constata que na modernidade passou a ser necessário domesticar os indesejáveis e neutralizar os resistentes, para que estes se adaptassem ao novo sistema produtivo industrial capitalista. Os não domesticáveis e os resistentes (incapazes para o trabalho nas indústrias e os tidos como criminosos), ao modo de vida proposto, tornam-se os inimigos a serem combatidos e a eles coube a prisão como forma de controle e exercício de poder sobre os seus corpos desajustados a nova ordem.

A partir deste panorama, é possível considerar que, na contemporaneidade brasileira, o poder (discurso)-político punitivo elegeu como inimigo ou grupo que representa a inconveniência de existir os adolescentes já aqui ditos como estigmatizados. Este grupo social ao mesmo tempo em que é considerado pela sociedade como os principais algozes da insegurança pública e causadores de crimes bárbaros - o que, de fato, não representa a realidade criminal do país -, são também vítimas das ações violentas nas cidades, o que termina por representar a dizimação desta camada da população.

O Mapa da Violência de $2014^{4}$ (WAISELFISZ, 2014), demonstra que os adolescentes e jovens de até 29/30 anos figuram como os principais atores da cena da

\footnotetext{
${ }^{4}$ Disponível em: http://www.mapadaviolencia.org.br/pdf2014/Mapa2014_JovensBrasil_Preliminar.pdf
} 
criminalidade violenta e se situam tanto como vitimizadores, quanto como vítimas nos crimes nas periferias das grandes e médias cidades do Brasil. Tal constatação insere este grupo populacional no núcleo do cenário da violência, da criminalidade e do mundo prisional do país.

Tal percepção, que na sequência será analisada, certamente, esconde as principais causas da violência criminal no Brasil e fundamenta o crescimento da cultura do medo na sociedade brasileira, culminando na opressão e afastamento do acesso aos direitos fundamentais por parte dos setores da sociedade que são tratados de forma arbitrária, com autoritarismo e desrespeito. Inclusive Volpi (2001), em seus estudos, já desfez o mito de que os adolescentes infratores são os principais agentes da criminalidade nas grandes cidades brasileiras.

Entretanto, a opção do Sistema de Justiça Juvenil brasileiro tem sido pelo encarceramento, apesar dos adolescentes, em sua maioria, não praticarem crimes de maior potencial ofensivo. De acordo com os dados da pesquisa produzida pela Secretaria Geral da Presidência da República em parceria com a Secretaria Nacional da Juventude, designada de Mapa do Encarceramento de Jovens no Brasil ${ }^{5}$, o número de adolescentes encarcerados por cumprimento de medida socioeducativa, entre os anos de 2000 a 2012 , teve um ligeiro aumento na média nacional, partindo de 19.595 para 20.532. Esse dado desmascara a falsa ideia, ainda presente na sociedade brasileira, de que os adolescentes infratores não são punidos.

Por outro lado, a mesma pesquisa revela que, em 2012, o Brasil possuía 269 pessoas adultas encarceradas para cada 100 mil habitantes, enquanto que o número de adolescentes encarcerados era de 05 para cada 100 mil habitantes. Isso portanto, demonstra que, em relação aos delitos praticados pelos adultos, é ínfimo o número de atos infracionais cometidos pelos adolescentes, o que desmente a tese que culpabiliza os adolescentes pelos principais índices de criminalidade violenta no país. No mesmo sentido e para fins de comparação, no ano de 2012, foram cometidos por adolescentes no Brasil 1.963 homicídios e 47.094 foram praticados por adultos, o que representa que apenas $4 \%$ destes delitos foram cometidos por adolescentes neste período. Em relação a gravidade dos delitos, a pesquisa revela que, em 2012, entre os crimes praticados por adolescentes somente $11 \%$ corresponderam aos atos infracionais graves de homicídio e latrocínio; os

\footnotetext{
${ }^{5}$ Disponível em: http://juventude.gov.br/articles/0009/3230/mapa-encarceramento-jovens.pdf
} 
demais crimes eram referentes a ações contra o patrimônio: roubo e furto aproximadamente $45 \%$ e tráfico de drogas ilícitas $27 \%$.

Os dados do $9^{\circ}$ Anuário Brasileiro de Segurança Pública ${ }^{6}$ de 2015, também revelam a mesma tendência em relação à criminalidade juvenil no Brasil. A taxa de adolescentes em cumprimento de medida socioeducativa de internação por 100 mil habitantes passou de 97,7 em 2012 para 111,3 em 2013, o que representa uma variação no perídio de 13,35 para cima. Já no estado do Rio Grande do Sul, a taxa de internação para a mesma média populacional, ou seja, para cada 100 mil habitantes, no regime de internação no ano de 2012 foi de 59,5 e, em 2013, de 66,7, demonstrando um aumento na ordem de $7 \%$ na taxa de internação.

De acordo com o Anuário de 2015, houve um aumento de $10 \%$ na taxa de atos infracionais praticados pelos adolescentes, pois o número absoluto de adolescentes em cumprimento da medida privativa de liberdade saltou de 20.532, em 2012, para 23.066 em 2013. De forma geral, os atos infracionais cometidos em todo o país ficaram assim distribuídos: roubo representou $42 \%$, seguido pelo tráfico de drogas ilícitas com $24,8 \%$ e pelo homicídio com 9,2\%. O furto representou 3,6\%, a tentativa de homicídio 3,1\%, o porte ilegal de armas de fogo $2,45 \%$ e o latrocínio com $2,0 \%$.

Gráfico 1: Atos Infracionais cometidos no Brasil, 2013.

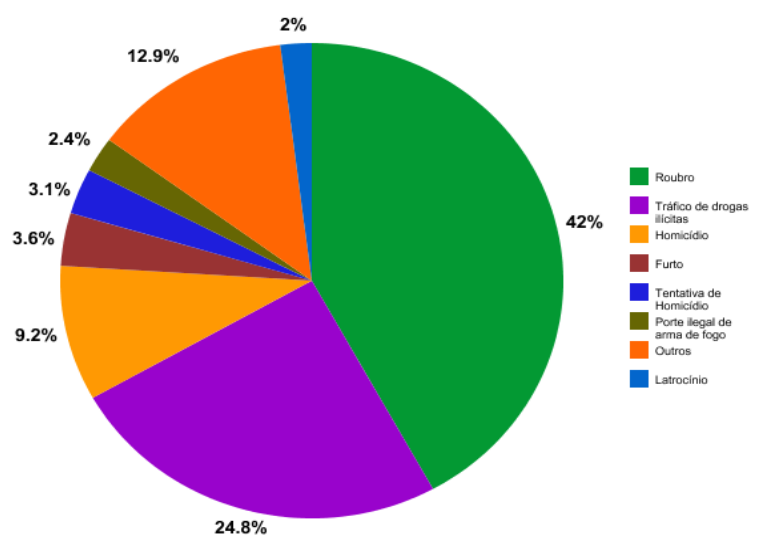

Fonte: Autores

\footnotetext{
${ }^{6}$ Disponível em: http://www.forumseguranca.org.br/storage/9_anuario_2015.retificado_.pdf
} 
De maneira geral, os dados referentes a tipicidade dos atos infracionais que determinam a internação dos adolescentes corroboram a mesma tendência do âmbito nacional. Quer dizer que, os atos infracionais que mais resultam no encarceramento são aqueles vinculados ao patrimônio e ao tráfico de drogas ilícitas, não os crimes contra pessoas.

Segundo dados disponibilizados pela Fundação de Atendimento Sócio Educativo do RS (FASERS) ${ }^{7}$, em setembro de 2014, haviam 1.202 adolescentes internados, destes, 519 ou $43 \%$ do total estavam internados por terem praticado roubo; 178 ou $14,8 \%$ por tráfico de drogas ilícitas; 22 ou 1,85\% por furto; 197 ou 16,4\% por homicídio; 88 ou 7,3\% por latrocínio e o restante distribuído pelos atos infracionais de menor potencial ofensivo.

O cenário do encarceramento juvenil, no ano de 2015, sofreu uma pequena variação em relação ao número de adolescentes internados, sete a menos do que em setembro de 2014, totalizando 1.195 , sendo destes 514 ou $43 \%$ pela prática do roubo; 181 ou $15,1 \%$ por homicídio; 140 ou 11,7\% por tráfico de drogas ilícitas; 94 ou 7,9\% por tentativa de homicídio; 48 ou 4\% por latrocínio; 20 ou 1,7\% por porte ilegal de drogas; 19 ou 1,6\% por estupro e 17 ou 1,4\% por furto, entre outros de menor incidência.

Percebe-se, a partir dos dados expostos que a ocorre entre ao ano de 2013 e o ano de 2015 uma pequena variação na espécies de crimes cometidos, surgem taxas de estupro, porte ilegal e tentativa de homicídio que não haviam sido colocadas nas estatísticas da FASERS. Contudo, mesmo com a inserção de tipos penais, a grande maioria dos atos infracionais continuam sendo de crimes contra o patrimônio e não contra a vida.

Gráfico 2: Atos Infracionais Cometidos no RS, 2013-2014

Infracionais Cometidos no RS, 2015

\footnotetext{
${ }^{7}$ Disponível em: http://www.fase.rs.gov.br/wp/dados_estatisticos/
} 


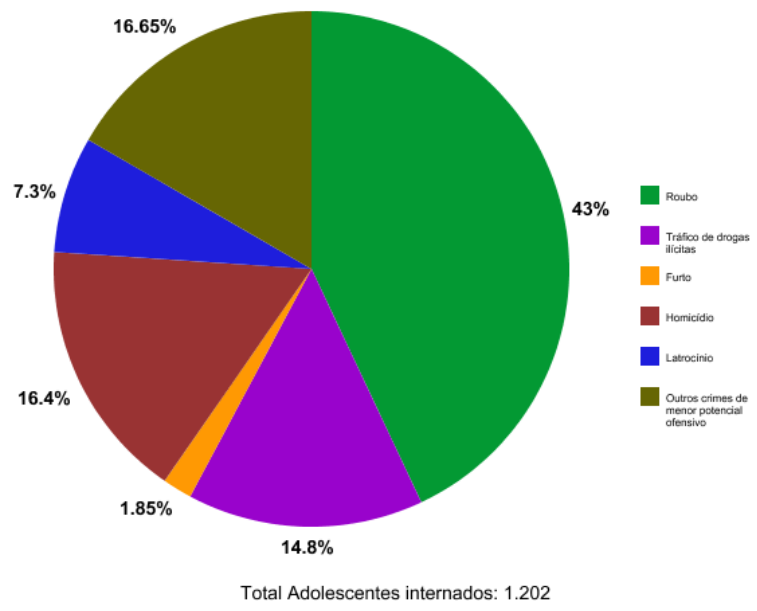

Fonte: Autores

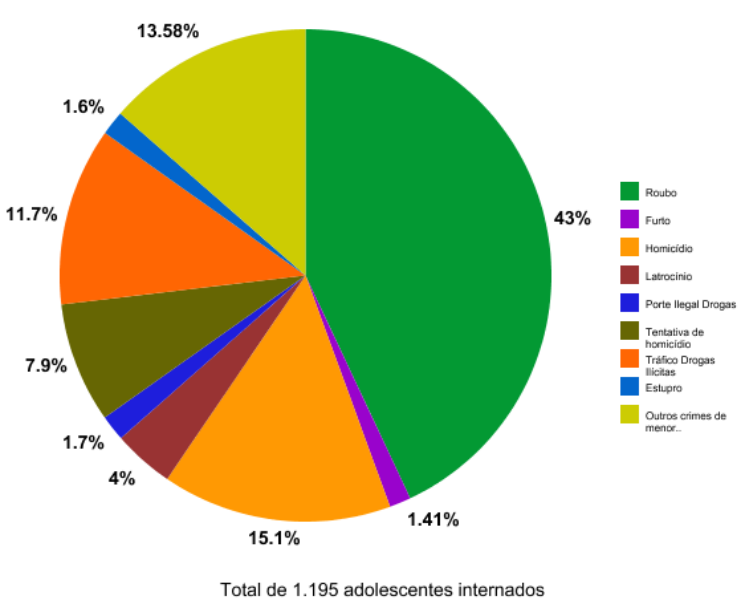

Fonte: Autores

Para Sinhoretto (2014), organizadora do Mapa do Encarceramento no Brasil, a combinação dos dados de pesquisa revela que o sistema de justiça juvenil brasileiro atua de forma seletiva e direcionada a uma determinada parcela da população juvenil: os estigmatizados pela idade, condição socioeconômica, raça, sexo, grau de escolaridade e local de residência. Isto significa dizer que para as camadas superiores e brancas da sociedade há pouca repressão penal, enquanto que para as camadas mais inferiores da pirâmide estatal cabe pouca atenção estatal na resolução dos conflitos e muita repressão penal sobre seus modos de viver, trabalhar, comerciar e se divertir. Ou seja, esta é a categoria populacional identificada como inimiga da sociedade e do Estado que não consegue se adaptar ao modelo de vida proposto e, por isso, merece ser encarcerada.

Por outro lado, uma parcela dos adolescentes e da juventude brasileira, de 15 a 30 anos, também se constitui como categoria social considerada inimiga da sociedade e do Estado, tendo a sua existência como inconveniente, pois, figuram como vítimas prioritárias da violência criminal através de homicídios por arma de fogo. A partir dos dados contidos no Mapa da Violência de $2016^{8}$ (WAISELFIZ, 2016) é possível constatar que, entre 1980 e 2014, morreram 967.851 pessoas vítimas de disparo por algum tipo de arma de fogo. Durante este período as vítimas passaram de 8.710 para 44.861, o que representa um crescimento de 415,1\% no número de mortos por arma de fogo. Mesmo considerando o aumento populacional do período que ficou em torno de $65 \%$, o saldo líquido de mortes por armas de fogo é muito grande.

\footnotetext{
${ }^{8}$ Disponível em: https://www.mapadaviolencia.org.br/pdf2016/Mapa2016_armas_web.pdf
} 
Ainda, segundo o Mapa da Violência do ano de 2016, foi a eclosão de homicídios por arma de fogo que fez disparar o aumento significativo da mortandade no Brasil, pois, nos 34 anos que o mapeamento abrange, tais mortes cresceram 592,8\%, setuplicando a taxa de 1980. Enquanto isso, o suicídio com arma de fogo aumentou 44,8\% e as mortes acidentais caíram 3,6\%, no mesmo período. Já as mortes por causa indeterminada, aquelas que não se sabe exatamente qual a causa (suicídio, homicídio ou acidente), tiveram uma queda moderada de $20,4 \%$.

Desse modo, os homicídios representam, ao longo do período analisado, $85 \%$ do total de mortes por arma de fogo. Contudo, uma parcela das mortes de causas indeterminadas pode ser creditada como homicídio, o que torna possível afirmar que praticamente $95 \%$ das mortes por arma de fogo no Brasil tem como objetivo exterminar o outro.

O que Waiselfiz (2016) denomina de "geografia dos homicídios" demonstra que, os crimes com armas de fogo no Brasil, até meados da década de 1990, concentravam-se nas grandes capitais e regiões metropolitanas no país. Foi só a partir de então, que este tipo de homicídio se pulverizou, devido a grande expansão do desenvolvimento econômico em todas as regiões brasileiras, principalmente em direção aos municípios médios e até de pequeno porte do interior.

No que diz respeito ao perfil das vítimas dos homicídios por arma de fogo, o Mapa da Violência de 2016 demonstra que na média nacional 94,4\% são do sexo masculino e possuem entre 15 e 29 anos. Se no conjunto da população, no período de 1980 a 2014, o crescimento dos homicídios por arma de fogo foi de 592,8\%, na população jovem, este crescimento representa $699,5 \%$.

Em relação à cor das vítimas, o Mapa da Violência (2016) deixa claro que a juventude negra é a mais atingida pelos homicídios com arma de fogo. Durante o ano de 2003 foram cometidos 13.224 homicídios por arma de fogo contra pessoas brancas no Brasil e em 2014 esse número desce para 9.766, significando uma queda de $26,1 \%$. No mesmo período, o número de vítimas negras pula de 20.291 para 29.813, o que representa um aumento de $46,9 \%$.

Quanto as taxas por 100 mil habitantes, no período de 2003 e 2014, constata-se que há uma queda na taxa de homicídios por arma de fogo na população branca de 14,5 em 2003, para 10,6, em 2014. Em contrapartida, há um crescimento concomitante de 
homicídios por arma de fogo na população negra que, em 2003 tinha 24,9 homicídios por arma de fogo e em 2014, passou para 27,4 por 100 mil, o que revela um incremento na taxa de 9,9\%. Ou seja, a vitimização negra no Brasil que, em 2003 era de 71,7\% (isto é, proporcionalmente, morre $71,7 \%$ mais negros do que brancos), avança para $158,9 \%$, em 2014.

Gráfico 4: Taxa de Homicídio por AF por idade simples, 2014

Gráfico 5 : Taxa de HAF brancas e negras, 2014.

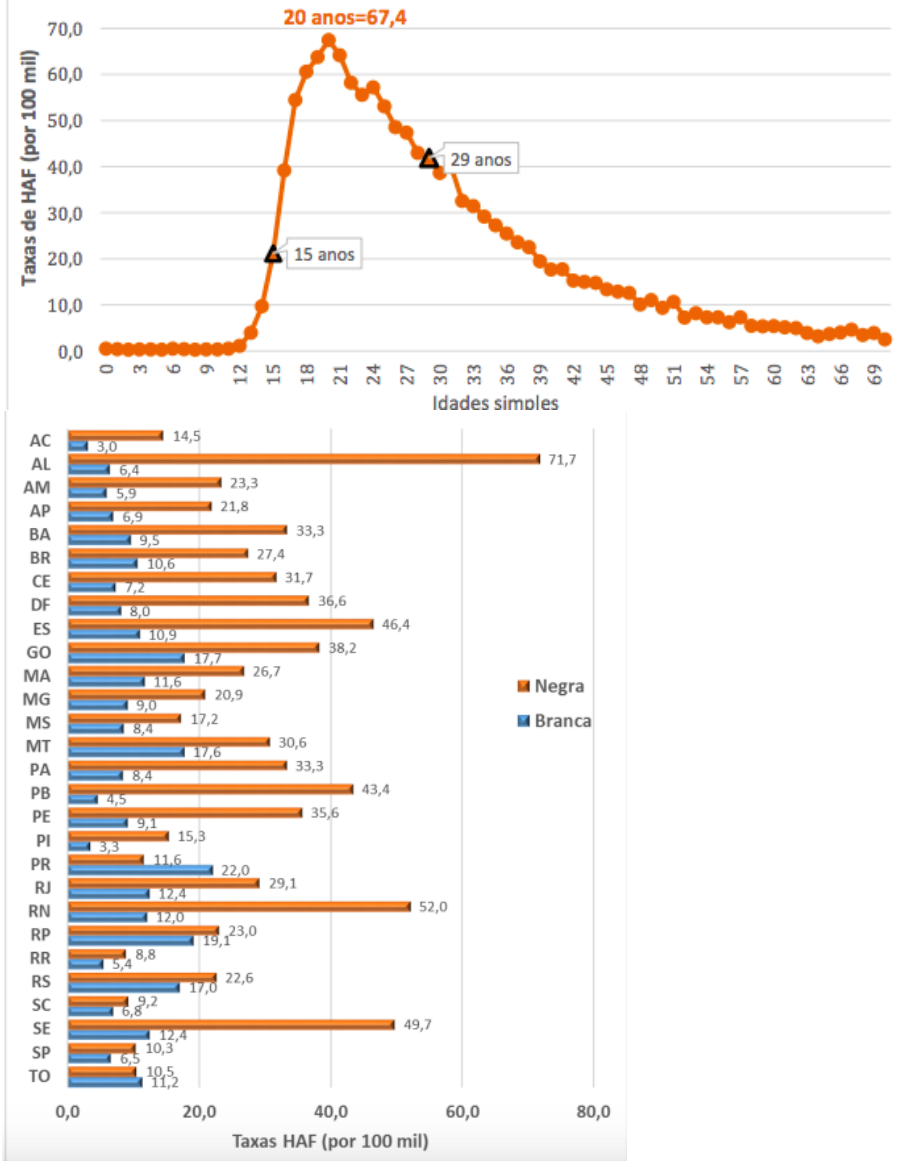

Fonte: Processamento Mapa da Violência 2016 Fonte: Processamento Mapa da Violência 2016

Cabe destacar, que a pesquisa realizada para a publicação do Mapa da Violência não adentra o mérito das causas destas mortes da população negra no Brasil. Contudo, é sabido que diferentes variáveis (criminais, étnicas, sociais, políticas e econômicas) interferem para tal conclusão, mas que não foram objeto de análise no estudo. 
Os dados analisados revelam que a sociedade brasileira elegeu uma parcela da população como sua inimiga. Isto é, jovens, pobres, negros e residentes das periferias nacionais, tornaram-se aqueles que Capeller (2005) denominou de "corpos matáveis", os descartáveis, que não despertam o sentimento de falta em outros setores sociais.

É por isso que cada vez mais esta população é encarcerada e exterminada por meio dos homicídios por armas de fogo e quando fazem isso, a sociedade e o Estado escondem de si próprios a falta de acesso aos direitos fundamentais por parte desta população e miram suas atenções em elementos que não reduzem ou eliminam um dos seus principais problemas: o medo da criminalidade violenta. Encarcerar cada vez mais esta população ou pretender reduzir a maioridade penal são iniciativas que não resultam na solução do problema, mas apenas postergam iniciativas vinculadas a políticas públicas de inserção digna e cidadã da juventude no mercado educacional, de trabalho e de consumo. Ocorre que, a sociedade e o Estado brasileiro omitem-se e a parcela estigmatizada - que é a majoritária - dos adolescentes e da juventude do país, nos dizeres populares: "se vira como pode" para resistir e sobreviver.

\section{CONCLUSÃO}

A consolidação do processo de globalização nas últimas décadas proporcionou mudanças drásticas nas formas de vidas dos atores sociais em todos os continentes do planeta. Novas formas de violências, de criminalidades e novos atores emergem na cena dos conflitos sociais. Como consequência disto, surgiu no seio social, o sentimento de medo, como o fruto da constituição e da percepção do risco, que é produto da sociedade moderna. (GIDDENS, 2000)

Paralelamente a isso, as sociedades, por interesses de determinado setores sociais, terminaram por eleger alguns grupos sociais como inimigos ou extermináveis por não se adaptarem ao padrão vigente. Conforme demonstraram os dados analisados neste estudo, extraídos de diversas fontes, a mídia e a elite política e econômica nacional elegeram uma parcela de adolescentes e jovens como os inimigos da sociedade e do Estado. Tal escolha se dá pelo fato de algum envolvimento em práticas delituosas e por pertencerem a classes sociais menos privilegiadas, o que legitimou no senso comum, a noção de que tal grupo 
revestido de estigma deveria ser encarcerado e até mesmo exterminado da sociedade "de bem" e seguidora das leis.

Conclui-se, mesmo sem encontrar uma solução segura para o tema abordado, que antes de tudo, é preciso repensar, reinventar a sociedade em que se vive. Entende-se que a cultura do medo afeta sobremaneira a vida da sociedade contemporânea. Com efeito, o presente artigo buscou demonstrar que a escolha, pelos setores dominantes da sociedade brasileira, além de revelar um grande equívoco no diagnóstico das causas da criminalidade no país, só potencializou o aumento da violência e da criminalidade, demonstrando uma enorme falta de sensibilidade quanto a formulação de políticas públicas garantidoras do acesso aos direitos fundamentais destes jovens.

Percebe-se que a estigmatização dos grupos sociais mais vulneráveis produziu efeitos que se expressão não somente em termos materiais, como o local de moradia, acesso à infraestrutura ou oportunidades de estudo e de emprego, mas também em termos práticos-simbólicos, pois os adolescentes e jovens pobres, negros e moradores das periferias personificam o perigo e, apesar dos dados estatísticos demonstrarem o contrário, não conseguem tirar de si o rótulo.

Os dados comprovam que não são os adolescentes e jovens infratores que carregam o estigmatizados os principais vitimizadores da sociedade, percebe-se, ao longo de toda a análise, que, na verdade, é justamente o contrário: estes são as vítimas de uma exclusão e também extermínio massivo.

Diante das reflexões de Bauman (2002) de que a exclusão não pode ser percebida como uma momentânea e irremediável mais sorte, mas como algo que tem a aparência de definitivo, e mais, ainda tende a ser uma via de mão única, é preciso resistir, buscar o fim da cultura brasileira criadora de indivíduos que carregam em si símbolos corporais e sociais que causam medo e, portanto, os determinam como perigos sociais. Apesar de muitos estudos já haverem se debruçado sobre as questões sociológicas e criminológicas acerca da cultura do medo nas sociedades modernas, os seus reflexos ainda continuam latentes, o que desafia os pesquisadores e também deveria desafiar a sociedade e o Estado a trabalhar a lutar pelo fim dos estigmas.

Resta a angústia de como superar o paradoxo brasileiro no qual os jovens negros, pobres, moradores das periferias nacionais foram estigmatizados como os maiores vitimadores, ou seja, os inimigos da sociedade, ao mesmo tempo em que são os as vítimas 
prioritárias da violência criminal. Como inverter a lógica brasileira que exclui, encarcera e mata todos os dias?

\section{REFERÊNCIAS}

BAUMAN, Zygmunt. O Mal-estar na Pós-modernidade. Rio de Janeiro: Jorge Zahar, 1998.

Medo Líquido. Rio de Janeiro: Jorge Zahar, 2008.

Confiança e Medo na Cidade. Rio de Janeiro: Jorge Zahar, 2009.

BRASIL. Os Jovens do Brasil: mapa da violência. Brasília: Secretaria-Geral da Segurança Pública, 2014. Disponível em: www.mapadaviolencia.org.br. Acesso em: 03/03/2018.

$8^{\circ}$ Anuário da Segurança Pública. Fórum Brasileiro de Segurança

Pública. São Paulo, 2014. Disponível em: www.forumseguranca.org.br. Acesso em: 25/02/2018.

$9^{\circ}$ Anuário da Segurança Pública. Fórum Brasileiro de Segurança Pública. São Paulo, 2015. Disponível em: www.forumseguranca.org.br. Acesso em: $10 / 11 / 2018$.

.Mapa do Encarceramento: Os jovens do Brasil. Secretaria Geral da Presidência da República e Secretaria Nacional da Juventude. Brasília, 2015. Disponível em: www.pnud.org.br/encarceramentoweb. Acesso em: 10/03/2018.

BECK, Ulrich. A Reinvenção da Política: rumo uma teoria da modernização reflexiva. In: LASCH, Scott; GIDDENS, Antony; BECK, Ulrich. Modernização Reflexiva- política, Tradição e Estética na Ordem Social Moderna. São Paulo: UNESP, 1997.

CARMO, Paulo Sérgio do. Culturas da Rebeldia: a juventude em questão. São Paulo: Senac, 2000.

CAPELLER, Wanda. De que Lugar Falamos? Retomando um velho papo sobre Direito e Sociologia. In: Revista de Estudos Empíricos em Direito. Vol. 2, n.1, jan 2015, p. 10-25. 
FRANÇA, Leandro Ayres. Inimigo ou a Inconveniência do Existir. Rio de janeiro: Lumen Juris, 2012.

FONSECA, Claudia. Família, Fofoca e Honra. Etnografia de relações de gênero e violência em grupos populares. 2 ed. Porto Alegre: UFRGS, 2004.

MAILLARD, Jean de. Crimes e Leis. Lisboa: Instituto Piaget, 1994.

MENDES, Ângela Dias Coelho; REIS, Rafael Felipe; SIMIONI, Rafael Lazzarotto. Direito, Risco e Confiança: o risco da modernidade em Anthony Giddens. In: MELlO, Marcelo Pereira de; PAULA, Quenya Correa de. (Orgs.) Pesquisa em Ação: Ética e práxis em Sociologia do Direito. Anais- V Congresso da ABRASD. Associação Brasileira em Sociologia do Direito. 19 a 21 de Novembro de 2014. Vitória, Espírito Santo. p. 2173-2185. Disponível em: www.abrasd.com.br/anais. Acesso em: 20/11/2017.

PASTANA, Débora Regina. Cultura do Medo e Democracia: um paradoxo brasileiro. Medições, $\quad$ v.10, N. 02/2005. Disponível em: www.eul.br/revistas/uel/index.php/mediacoes/article. Acesso em: 20/11/2017.

PORTO, Maria Stela Grossi. Sociologia da Violência: do conceito as representações sociais. Brasília: Francis, 2010.

RIO GRANDE DO SUL. Atos infracionais praticados pelos adolescentes privados de liberdade na FASERS, em 03/2018 e 04/2018. Disponível em: www.fase.rs.gov.br. Acesso em: 03/03/2018 e 04/04/2018.

SANTOS, Boaventura de Sousa. Pela Mão de Alice. O social e o político na pósmodernidade. São Paulo: Cortez, 2000.

SINHORETTO, Jaqueline. Apresentação do Mapa do Encarceramento: os jovens do Brasil, 2014, Brasília, 2015. Secretaria geral da Presidência da República e Secretaria Nacional da Juventude, Brasília, 2015. Disponível em: www.pnud.org.br/encarceramentoweb. Acesso em: 10/08/2015.

SOARES, Eduardo; BILl, MV; Athayde, Celso. Cabeça de Porco. Rio de Janeiro: Objetiva, 2005.

VOLPI, Mário. Sem Liberdade, sem Direitos. São Paulo: Cortez, 2001. 
WAISELFISZ, Julio Jacobo. Mapa da Violência 2016: homicídios por arma de fogo no Brasil. Brasília: Flacso Brasil, 2016.

ZALUAR, Alba. Integração Perversa: pobreza e tráfico de drogas. Rio de Janeiro: FGV, 2004.

Gangues, galeras e quadrilhas: globalização, juventude e violência. In:

VIANNA, Hermano. (Org.). Galeras cariocas. Territórios de conflitos e encontros culturais. Rio de Janeiro: UFRJ, 1997. 